\title{
LAPAROSCOPIC CHOLECYSTECTOMY; TIMING OF LAPAROSCOPIC CHOLECYSTECTOMY IN PATIENTS WITH MILD ACUTE BILIARY PANCREATITIS
}

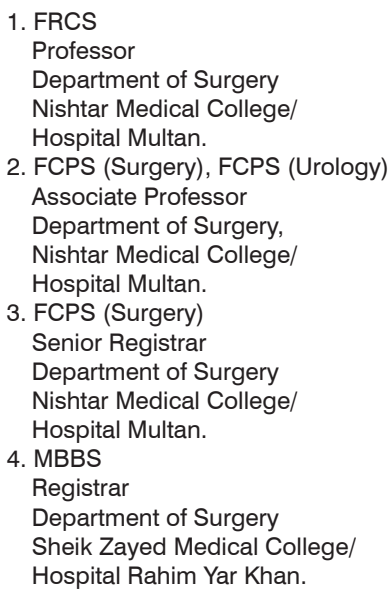

Correspondence Address:

Naveed Akhtar

Department of Surgery,

Nishtar Medical College/

Hospital Multan.

drchnaveed@yahoo.com

Article received on:

21/11/2017

Accepted for publication:

20/04/2018

Received after proof reading: 00/00/2018

\section{Mustma Kamal', Naveed Akhtar², Ghulam Murtaza ${ }^{3}$, Najaf Azad ${ }^{4}$}

ABSTRACT... Background: Gallstones and biliary sludge accounted for $30-55 \%$ of acute pancreatitis in the West whereas in other countries the incidence of all cases of pancreatitis amounts up to $68.5 \%$. The risk of subsequent attacks for patients recovering from the first attack of acute biliary pancreatitis is 30 -fold higher than general population. Further attacks can be prevented by cholecystectomy. Both immediate and delayed cholecystectomies are used with different degree of success and complication rates. Objectives: To compare the frequencies of complications in early and late cholecystectomy in cases of mild acute biliary pancreatitis. Material \& Methods:... Study Design: Randomized control trial. Setting: Surgical unit I Nishtar Medical College/ Hospital Multan. Duration of Study: 2 years from 1-1-2015 to 31-12-3016. Sample Size: Total 172 patients, 86 in each group. Sampling Technique: Nonprobability, consecutive sampling. Results: In this study there were total 172 cases out of which 89 (51.74\%) were males and 83 (48.26\%) females. The mean age was $42.02 \pm 6.36$ years and mean duration of symptoms was $4.08 \pm 2.54$ days. Mean duration of surgery was $53.30 \pm$ 6.30 minutes. There were 47 males in the group undergoing early cholecystectomy and 39 in delayed with $p=0.44$. Both groups had maximum cases in age group of $40-50$ year with $p=$ 0.39 . There was no significant difference in terms of duration of symptoms $(p=0.26)$ in both groups. There was significant difference in terms of prolonged duration of surgery where it was seen in $8(9.30 \%)$ out of 86 cases with early as compared to $2(2.33 \%)$ out of 86 cases with delayed cholecystectomy with $p$ value of 0.05 . Prolonged duration of hospital stay was also more seen in early cholecystectomy as compared to delayed one, seen in 10 (11.63) cases in early and $4(4.65 \%)$ cases with delayed surgery in their respective groups with $p=0.09$. There was significant difference $(p=0.008)$ in terms of per operative complication with early surgery where it affected the $18(20.93 \%)$ cases as compared to delayed one with 6 (6.95\%) cases. There was again significant difference shown in terms of recurrence of pancreatitis which was seen in $7(8.14 \%)$ of cases with early as compared to $1(1.16 \%)$ with delayed surgery with $p=0.03$. Conclusion: Early and late cholecystectomies both are performed in tertiary care hospitals. The late cholecystectomy has shown significantly lower per operative complications, duration of surgery and chances of the recurrent pancreatitis.

Key words: $\quad$ Acute Biliary Pancreatitis, Early and Delayed Cholecystectomy.

Article Citation: Kamal M, Akhtar N, Murtaza G, Azad N. Laparoscopic cholecystectomy; timing of laparoscopic cholecystectomy in patients with mild acute biliary pancreatitis. Professional Med J 2018; 25(7):1046-1053.

DOI:10.29309/TPMJ/18.4523

\section{INTRODUCTION}

Acute pancreatitis is a common gastrointestinal disorder and in the majority of patients the etiology is either alcohol-associated or biliary, i.e. caused by gallstones or sludge., ${ }^{1,2}$ The incidence of acute biliary pancreatitis is increasing worldwide, possibly due to an increased risk of gallstone disease due to nutritional and lifestyle factors and obesity. ${ }^{3,4}$ The economic burden of acute pancreatitis is high; In the United States alone, the annual costs of acute pancreatitis currently exceed $\$ 2.2$ billion (10). The majority of patients with acute pancreatitis (80\%) have a mild course of their disease, but $20 \%$ of patients develop severe pancreatitis, which is associated with high morbidity and mortality. ${ }^{5}$ Once biliary pancreatitis is resolved, cholecystectomy is indicated to reduce the risk of recurrent gallstonerelated complications such as acute pancreatitis, cholecystitis, cholangitis or gallstone colics.6,7 
A much discussed question is when during the course of pancreatitis the gallbladder should be removed.

High complication and mortality rates after early cholecystectomy in patients with severe pancreatitis have prompted guidelines recommending delaying cholecystectomy until all signs of inflammation have resolved (i.e. interval cholecystectomy).,8,9 After mild biliary pancreatitis early cholecystectomy is advised by current guidelines., ${ }^{7,11}$ However, no consensus exists between these guidelines about the exact definition of 'early'. The British Society of Gastroenterology recommended cholecystectomy within 2 weeks after discharge, whereas the International Association of Pancreatology (IAP) and the American Gastroenterological Association recommend that all patients with mild biliary pancreatitis should undergo cholecystectomy as soon as the patient has recovered from the attack. ${ }^{6,7,11}$ However, in contrast with these guidelines, in daily practice cholecystectomy after mild biliary pancreatitis is often postponed for several weeks after hospital discharge (interval cholecystectomy). Nationwide audits from Europe and the United States have shown that laparoscopic cholecystectomy is usually performed around 6 weeks after discharge from hospital admission for mild biliary pancreatitis. ${ }^{12,13,14,15,16,17,18,19,20}$ A perceived danger of perioperative complications in early cholecystectomy after acute pancreatitis is the main reason for this delay in cholecystectomy. . $^{21,22}$ It is believed that distorted biliary tract anatomy by inflammation and edema may complicate dissection with a higher risk of conversion and surgical complications, such as bile duct injury ${ }^{23,24,25}$ Another reason is that a delayed approach facilitates surgical scheduling, as emergency theatre capacity is often limited. ${ }^{21}$

\section{OBJECTIVES}

To compare the frequencies of complications in early and late cholecystectomy in cases of acute biliary pancreatitis.

\section{Acute Biliary Pancreatitis}

Patients will be labeled as a case of acute biliary pancreatitis if presents with all of these within seven days of the symptoms;

- Abdominal pain (above or around umbilicus) of severe intensity.

- serum amylase of $>3$ times of normal upper lab value (normal range is $23-85 \mathrm{U} / \mathrm{L}$ )

- ultrasound abdomen showing stones in Gall bladder of any size/number

\section{Cholecystectomy}

Surgical removal of gall bladder is called cholecystectomy.

\section{Early}

Cholecystectomy done within 48 hours relief of symptoms of acute biliary pancreatitis.

\section{Late}

Cholecystectomy done after 6 weeks relief of symptoms of acute biliary pancreatitis.

\section{Perioperative Complications}

This will be considered if anyone or more of the following present

a. $>100 \mathrm{ml}$ of greenish fluid in drain in first $24 \mathrm{hr}$ post operatively

b. $>50 \mathrm{ml}$ blood loss per-operatively

c. Conversion of laparoscopic cholecystectomy into open cholecystectomy due to difficult surgery.

\section{Prolonged Hospital Stay}

It will be labeled when the hospital stay is more than 5 days after the surgery.

\section{Prolonged Duration of Surgery}

It will be labeled when the duration of surgery from incision to closure will be more than 60 minutes.

\section{Recurrence of Pancreatitis}

It will be considered if patient presents again with the symptoms of biliary pancreatitis within 6 weeks of initial attack.

\section{MATERIAL AND METHOD \\ Study Design \\ Randomized control trial}


Settings

Surgical unit I, Nishtar Medical College/ Hospital Multan.

\section{Duration of Study}

2 years from 1-1-2015 to 31-12-3016.

\section{Sample Size}

The sample size was calculated as 86 in each group using $\mathrm{WHO}$ sample size calculator by keeping the power equal to $80 \%$ and significant equal to $5 \%$ using prevalence of prolonged duration of surgery in early cholecystectomy in $10 \%$ and in delayed in $0.4 \%$ of cases.

\section{Sample Technique}

Non probability consecutive sampling.

\section{SAMPLE SELECTION}

\section{Inclusion Criteria}

1. All the patients of both genders between 20 to 50 years of age.

2. Patients with first attack of acute biliary pancreatitis within seven days of the symptoms.

\section{Exclusion Criteria}

1. Alcoholics.

2. Patients presenting with complications like pseudo cyst, phlegmon, necrotizing pancreatitis assessed on ultrasound abdomen.

3. Recurrent attacks of pancreatitis

4. Bilirubin level $>4 \mathrm{mg} / \mathrm{dl}$

5. History of Diabetes mellitus, Coagulopathies, steroids and preoperative any Malignancy.

\section{DATA COLLECTION PROCEDURE}

This study will be conducted after taking permission from the hospital ethical committee and informed consent from the patients. All the patients presenting in Sheikh Zayed hospital emergency fulfilling the above mentioned criteria will be enrolled in this study. After taking the sociodemographic data they will be divided in two groups ( $A=$ early, $B=$ late surgery) by shield opaque envelop method and will undergo laparoscopic cholecystectomy in Sheikh Zayed Hospital, Rahim yar khan according to timing of their respective group (early/late) as per operational definition. They will be assessed for perioperative complications in terms of blood loss during surgery, conversion of laparoscopic to open surgery and greenish fluid in the drain for next 24 hours. Time of surgery will also be noted from the incision up to closure of the wound. Patients will then be noted for their hospital stay till discharge and time is noted in days. Patients will be followed daily for in-hospital and on weekly basis after discharge for complication like recurrence of pancreatitis by history, serum amylase and USG abdomen and final outcome will be seen at six weeks of surgery. Data will be collected and recorded on a pre-defined proforma.

\section{DATA ANALYSIS PROCEDURE}

Collected data will be analyzed by SPSS ver. 20 . Qualitative variables like gender, type of surgery (early or late) and complications i.e. perioperative complications, prolonged duration of surgery, prolonged hospital stay and recurrence of pancreatitis will be presented in terms of frequency and percentages and quantitative variables like age, duration of symptoms, pain on VAS, duration of surgery, duration of hospital stay and time for recurrence of pancreatitis will be presented in terms of mean \pm SD. Effect modifiers will be stratified through gender, age, duration of symptoms and type of surgery to see its effect on outcome variable (perioperative complication, prolonged duration of surgery, prolonged hospital stay, recurrence of pancreatitis). Two groups will be compared for complications by applying chi square test and $p$ value $<0.05$ will be considered significant.

\section{RESULTS}

In this study there are total 172 cases, out of which $89(51.74 \%)$ were males and $83(48.26 \%)$ females as shown in Figure-1. The mean age was $42.02 \pm$ 6.36 years and mean duration of symptoms was $4.08 \pm 2.54$ days as shown in Figure-2 \& Table-l. Mean duration of surgery was $53.30 \pm 6.30$ minutes as in Table-II. There were 47 males in the group undergoing early cholecystectomy and 39 in delayed with $p=0.44$. 39 females in early group and 44 in late group as shown in Table-III. 
Both groups had maximum cases in age group of 40-50 year with $p=0.39$ as in Table-IV. There was no significant difference in terms of duration of symptoms $(p=0.26)$ in both groups as in Table-V. Table-VI reveals that there was significant difference in terms of prolonged duration of surgery where it was seen in $8(9.30 \%)$ out of 86 cases with early as compared to $2(2.33 \%)$ out of 86 cases with delayed cholecystectomy with $p$ value of 0.05 . Prolonged duration of hospital stay was also more seen in early cholecystectomy as compared to delayed one, seen in 10 (11.63) cases in early and $4(4.65 \%)$ cases with delayed surgery in their respective groups with $p=0.09$ as in Table-VII. There was significant difference $(p=$ 0.008 ) in terms of per operative complication with early surgery where it affected the 18 (20.93\%) cases as compared to delayed one with 6 $(6.95 \%)$ cases as displayed in Table-VIII. There was again significant difference shown in terms of recurrence of pancreatitis which was seen in $7(8.14 \%)$ of cases with early as compared to 1 $(1.16 \%)$ with delayed surgery with $p=0.03$ as in Table-IX.

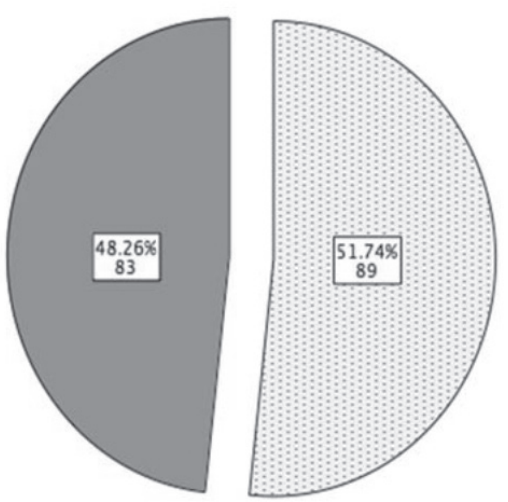

Figure-1. Gender distribution of study subjects $n=172$

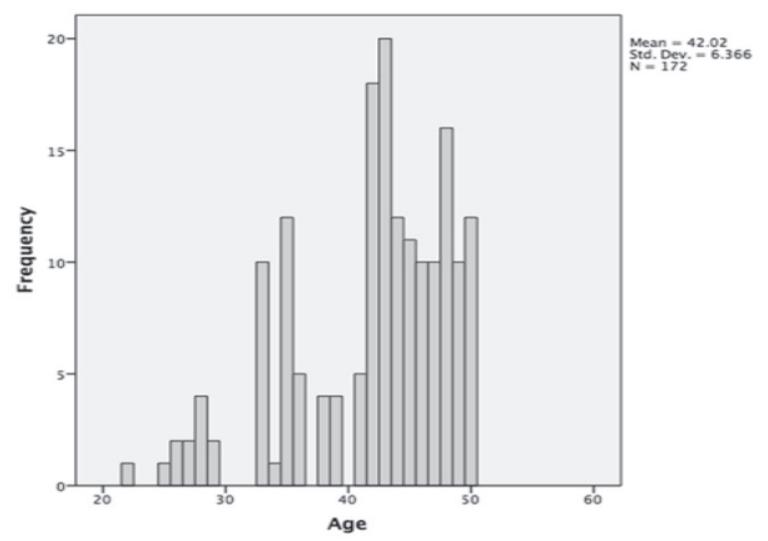

Figure-2. Age distribution of study subjects $n=172$

Variables

Age Duration of Symptoms (days)

\begin{tabular}{|l|c|c|c|}
\hline Mean & 42.02 & 4.08 \\
\hline 95\% Confidence Interval & Lower Bound & 41.06 & 3.69 \\
\cline { 2 - 4 } for Mean & Upper Bound & 42.98 & 4.46 \\
\hline Median & & 42.00 & 3.00 \\
\hline Std. Deviation & 6.36 & 2.54 \\
\hline Minimum & 22 & 1 \\
\hline Maximum & 50 & 14
\end{tabular}

Table-I. Study variables (Age \& duration of symptoms) $n=172$

\begin{tabular}{|c|c|c|c|c|}
\hline & \multicolumn{3}{|c|}{ Variables } \\
\hline & & Duration of Surgery & Duration of Hospital Stay & Duration of Surgery \\
\hline \multicolumn{2}{|l|}{ Mean } & 53.30 & 3.53 & 3.14 \\
\hline \multirow{2}{*}{$\begin{array}{l}95 \% \text { Confidence Interval for } \\
\text { Mean }\end{array}$} & Lower Bound & 52.35 & 3.27 & 2.50 \\
\hline & Upper Bound & 54.25 & 3.80 & 3.78 \\
\hline \multicolumn{2}{|l|}{ Median } & 55.00 & 3.00 & 3.00 \\
\hline \multicolumn{2}{|l|}{ Std. Deviation } & 6.31 & 1.75 & 0.69 \\
\hline \multicolumn{2}{|l|}{ Minimum } & 40 & 2 & 2 \\
\hline \multicolumn{2}{|l|}{ Maximum } & 80 & 15 & 14 \\
\hline
\end{tabular}

Professional Med J 2018;25(7):1046-1053. 


\begin{tabular}{|c|c|c|c|}
\hline \multirow{2}{*}{ Gender } & \multicolumn{2}{|c|}{ Type of Surgery } & \multirow{2}{*}{ Total } \\
\hline & Early $n=86$ & Late $n=86$ & \\
\hline Male & 47 (54.65\%) & 42 (48.84\%) & 89 \\
\hline Total & 86 (100\%) & 86 (100\%) & 172 (100\%) \\
\hline
\end{tabular}

\begin{tabular}{|l|c|c|c|}
\hline \multirow{2}{*}{ Age Groups (Years) } & \multicolumn{2}{|c|}{ Type of Surgery } & Total \\
\hline $20-29$ & Early $\mathbf{n = 8 6}$ & $5(5.81 \%)$ & 12 \\
\hline $30-39$ & $7(8.14 \%)$ & $22(25.58 \%)$ & 37 \\
\hline $40-50$ & $15(17.44 \%)$ & $59(68.61 \%)$ & 123 \\
\hline Total & $64(74.12 \%)$ & $86(100 \%)$ & $172(100 \%)$ \\
\hline
\end{tabular}

Table-IV. Type of surgery with respect to age groups $n=172$ (Chi square $=1.86, p=0.39$ )

\begin{tabular}{|l|c|c|c|}
\hline \multirow{2}{*}{ Duration of Symptoms } & \multicolumn{2}{|c|}{ Type of Surgery } & \multirow{2}{*}{ Total } \\
\hline 3 days or less & Early $\mathbf{n = 8 6}$ & Late $\mathbf{n = 8 6}$ & 113 \\
\hline$>3$ days & $53(61.63 \%)$ & $60(69.77 \%)$ & 59 \\
\hline Total & $33(38.37 \%)$ & $26(30.23 \%)$ & $172(100 \%)$ \\
\hline
\end{tabular}

Table-V. Type of surgery with respect to duration of symptoms $n=172$ (Chi square $=1.26, p=0.26)$

\begin{tabular}{|l|c|c|c|}
\hline \multirow{2}{*}{$\begin{array}{c}\text { Prolonged Duration of } \\
\text { Surgery }\end{array}$} & \multicolumn{2}{|c|}{ Type of Surgery } & \multirow{2}{*}{ Total } \\
\cline { 2 - 4 } & Early $\mathbf{n = 8 6}$ & Late $\mathbf{n = 8 6}$ & $10(100 \%)$ \\
\hline Yes & $8(9.30 \%)$ & $2(2.33 \%)$ & $162(100 \%)$ \\
\hline To & $78(90.70 \%)$ & $84(97.67 \%)$ & $172(100 \%)$ \\
\hline
\end{tabular}

Table-VI. Prolonged duration of surgery with respect to type of surgery $n=172$ (Chi square $=3.82, p=0.05$ )

\begin{tabular}{|l|c|c|c|}
\hline \multirow{2}{*}{$\begin{array}{c}\text { Prolonged Duration of } \\
\text { Hospital Stay }\end{array}$} & \multicolumn{2}{|c|}{ Type of Surgery } & Total \\
\hline Yes & $10(11.63 \%)$ & Late $\mathbf{n = 8 6}$ & 14 \\
\hline No & $76(88.37 \%)$ & $04(4.65 \%)$ & 158 \\
\hline Total & $86(100 \%)$ & $82(95.35 \%)$ & $172(100 \%)$ \\
\hline
\end{tabular}

Table-VII. Prolonged duration of hospital stay with respect to type of surgery $n=172$ (Chi square $=2.79, p=0.09)$

\begin{tabular}{|l|c|c|c|}
\hline \multirow{2}{*}{$\begin{array}{c}\text { Per Operative } \\
\text { Complications }\end{array}$} & \multicolumn{2}{|c|}{ Type of Surgery } & \multirow{2}{*}{ Total } \\
\hline Yes & $18(20.93 \%)$ & Late $\mathbf{n = 8 6}$ & 24 \\
\hline No & $68(79.07 \%)$ & $06(6.98 \%)$ & 148 \\
\hline Total & $86(100 \%)$ & $80(93.02 \%)$ & $172(100 \%)$ \\
\hline
\end{tabular}

Table-VIII. Per operative complications with respect to type of surgery $n=172$ (Chi square $=6.97, p=0.008$ )

\begin{tabular}{|c|c|c|c|}
\hline \multirow{2}{*}{ Recurrence of Pancreatitis } & \multicolumn{2}{|c|}{ Type of Surgery } & \multirow{2}{*}{ Total } \\
\hline & Early $n=86$ & Late $n=86$ & \\
\hline Yes & $07(8.14 \%)$ & $01(1.16 \%)$ & 08 \\
\hline No & 79 (91.86\%) & $85(98.84 \%)$ & 164 \\
\hline Total & $86(100 \%)$ & $86(100 \%)$ & $172(100 \%)$ \\
\hline
\end{tabular}




\section{DISCUSSION}

In this study considering the duration of surgery, there was significant difference in terms of prolonged duration of surgery between two groups, where it was seen in $8(9.30 \%)$ out of 86 cases with early as compared to $2(2.33 \%)$ out of 86 cases with delayed cholecystectomy with $p$ value of 0.05 . This was also observed by many other studies where they found the longer duration of surgery with number of cases higher with early cholecystectomy. ${ }^{26,27,28}$ According to a study done by Jee $S L$ et $\mathrm{al}^{26}$ there was no significant difference seen in both the groups and the cases with early cholecystectomy were completed in 85 minutes as compared to 80 with late cholecystectomy with $p$ value of 0.75 . The reason of the higher number with early cholecystectomy can be explained by the acute inflammatory condition of the viscera in which it takes longer to deal with the inflamed tissue. Secondly, the cases with acute conditions like spillage and massive inflammation also take longer to flush the viscera and decontaminate; hence leading to prolonged duration of surgery.

Prolonged duration of hospital stay was also more seen in early cholecystectomy as compared to delayed one, seen in $10(11.63 \%)$ cases in early and $4(4.65 \%)$ cases with delayed surgery in their respective groups. However, this difference was not found statistically significant with $p=$ 0.09 . This was also noted by studies done in the past. ${ }^{29,30}$ This can be explained in many ways. First of all the cases presenting with acute pain are in more agony and hence relief of pain takes longer and hence affect their hospital stay. Secondly, when they present in acute stage as compared to the delayed group where they are treated with antibiotics and anti-inflammatory agents, the inflammation and acute infection both are settled. That's why the chances of further pain and inflammation leading to delay in healing and more symptoms are also decreased with late surgery. Thirdly, the psychiatry of the patients in terms of urgent surgery as compared to elective one can also be another factor that can help them with early mobilization and shorter hospital stay. In contrast to this, a study conducted by Aboulian A et al revealed shorter hospital stay with early cholecystectomies. However, they used slightly longer time where they performed surgery after 48 hours of admission rather than on the same day. ${ }^{31}$

There was significant difference $(p=0.008)$ in terms of per operative complication with early surgery where it affected the $18(20.93 \%)$ cases as compared to delayed one with $6(6.95 \%)$ cases out of their 86 cases in each group. This was also observed by other studies that have assessed for different parameters regarding the per operative complications, however the difference was not found statistically significant. ${ }^{32,33}$ Although data not mentioned, but the most common types of per operative complication in our surgery was increased amount of blood loss and conversion of the laparoscopic surgery to an open surgery in cases with early cholecystectomy. According to a study done by Nebiker CA et $\mathrm{al}^{33}$ the conversion of laparoscopic surgery to open was seen in $6 \%$ with early and $3 \%$ with delayed cholecystectomy. Per operative bleeding and bile leakage was seen in 3 and $4 \%$ respectively with early and delayed surgery. The reason behind the higher cases with early surgery again cover the same pathophysiology that in acute cases there is marked inflammation that interfere with the proper surgical approached and secondly the infection of the surrounding viscera and the cavity also predispose to more chances of biliary leak. Fragility of the vessel and rough handling can also be a cause with more bleeding which was one of the parameter of per operative complications. Moreover, combining all these factors with bile leak, excessive bleeding and inflammatory exudate also lead to poor view and larger inflammatory burden led to conversion of laparoscopic surgery to conventional open laparotomy. On the other hand the cases with delayed cholecystectomies had time to settle for infections and inflammation that led to better surgical approach and lesser complication rates.

There was again significant difference shown in terms of recurrence of pancreatitis which was seen in 7 (8.14\%) of cases with early as compared to $1(1.16 \%)$ with delayed surgery with $p=0.03$. The studies have shown mixed results with few shown recurrence in early and few delayed 
cholecystectomies but none of them have shown any significant association with this. ${ }^{34,35,36}$ The reason of this significantly higher number with early cholecystectomy in our study is unknown. The chance of higher rate of recurrence can be improper surgery that led to remaining of the stones that were dislodged and obstructed the bile duct and led to recurrence of pancreatitis. Inflammatory mediators also lead to cholestasis, which can also be a cause of retrograde inflammation and pancreatitis.

There were many strengths of this study, as this was done to compare the most reported and concerned points regarding the cholecystectomy and have found many significant differences.

However, there were few limitations too. As this study did not check for number and size of the stones involved and it also did not check for long term follow ups.

\section{CONCLUSION}

Early and late cholecystectomies both are performed in tertiary care hospitals. The late cholecystectomy has shown significantly lower per operative complications, duration of surgery and chances of the recurrent pancreatitis.

Copyright(C) 20 Apr, 2018.

\section{REFERENCES}

1. Isenmann R, Rau B, Beger HG. Early severe acute pancreatitis: characteristics of a new subgroup. Pancreas 2001; 22:274.

2. Talukdar R, Swaroop Vege S. Early management of severe acute pancreatitis. Curr Gastroenterol Rep 2011; 13:123.

3. Telem DA, Bowman K, Hwang J, Chin EH, Nguyen SQ, Divino CM. Selective management of patients with acute biliary pancreatitis. J Gastrointest Surg. 2009 Dec. 13(12):2183-8.

4. Whitcomb DC, Muddana V, Langmead CJ, et al. Angiopoietin-2, a regulator of vascular permeability in inflammation, is associated with persistent organ failure in patients with acute pancreatitis from the United States and Germany. Am J Gastroenterol 2010; 105:2287.

5. Vege SS, Yadav D, Chari ST. Pancreatitis. In: GI Epidemiology, 1st ed, Talley NJ, Locke GR, Saito YA
(Eds), Blackwell Publishing, Malden, MA 2007.

6. Balthazar EJ, Ranson JH, Naidich DP, Megibow AJ, Caccavale R, Cooper MM. Acute pancreatitis: prognostic value of CT. Radiology. 1985 Sep. 156(3):767-72. [Medline].

7. Mofidi R, Duff MD, Wigmore SJ, et al. Association between early systemic inflammatory response, severity of multiorgan dysfunction and death in acute pancreatitis. Br J Surg 2006; 93:738.

8. Parenti DM, Steinberg W, Kang P. Infectious causes of acute pancreatitis. Pancreas 1996; 13:356.

9. Singla A, Csikesz NG, Simons JP, Li YF, Ng SC, Tseng JF, et al. National hospital volume in acute pancreatitis: analysis of the Nationwide Inpatient Sample 19982006. HPB (Oxford). 2009 Aug. 11(5):391-7.

10. Venneman NG, Renooij W, Rehfeld JF, et al. Small gallstones, preserved gallbladder motility, and fast crystallization are associated with pancreatitis. Hepatology 2005; 41:738.

11. Johnson C, Charnley R, Rowlands B, et al. UK guidelines for the management of acute pancreatitis. Gut 2005; 54 Suppl 3:1.

12. Banks PA, Freeman ML, Practice Parameters Committee of the American College of Gastroenterology. Practice guidelines in acute pancreatitis. Am J Gastroenterol 2006; 101:2379.

13. Rattner DW. Experimental models of acute pancreatitis and their relevance to human disease. Scand J Gastroenterol Suppl 1996; 219:6.

14. Li H, Qian Z, Liu Z, Liu X, Han X, Kang H. Risk factors and outcome of acute renal failure in patients with severe acute pancreatitis. J Crit Care. 2010 Jun. 25(2):225-9.

15. Dassopoulos T, Ehrenpreis ED. Acute pancreatitis in human immunodeficiency virus-infected patients: a review. Am J Med 1999; 107:78.

16. Morinville VD, Barmada MM, Lowe ME. Increasing incidence of acute pancreatitis at an American pediatric tertiary care center: is greater awareness among physicians responsible?. Pancreas. 2010 Jan. 39(1):5-8. [Medline].

17. Akhtar AJ, Shaheen M. Extra pancreatic manifestations of acute pancreatitis in African-American and Hispanic patients. Pancreas. 2004 Nov. 29(4):291-7.

18. Tenner S, Baillie J, Dewitt J, et al. American College of Gastroenterology Guidelines: Management of Acute Pancreatitis. Am J Gastroenterol. 2013 Jul 30. 
19. Whitcomb DC. Clinical practice. Acute pancreatitis. $N$ Engl J Med. 2006 May 18. 354(20):2142-50. [Medline].

20. Balthazar EJ, Robinson DL, Megibow AJ, Ranson $\mathrm{JH}$. Acute pancreatitis: value of CT in establishing prognosis. Radiology. 1990 Feb. 174(2):331-6.

21. Granger J, Remick D. Acute pancreatitis: models, markers, and mediators. Shock. 2005 Dec. 24 Suppl 1:45-51.

22. Morinville VD, Barmada MM, Lowe ME. Increasing incidence of acute pancreatitis at an American pediatric tertiary care center: is greater awareness among physicians responsible?. Pancreas. 2010 Jan. 39(1):5-8. [Medline].

23. Ettestad PJ, Campbell GL, Welbel SF, et al. Biliary complications in the treatment of unsubstantiated Lyme disease. J Infect Dis 1995; 171:356.

24. Parenti DM, Steinberg W, Kang P. Infectious causes of acute pancreatitis. Pancreas 1996; 13:356.

25. Imamura $\mathrm{Y}$, Hirota $\mathrm{M}$, Ida $\mathrm{S}$, Hayashi $\mathrm{N}$, Watanabe $\mathrm{M}$, Takamori $\mathrm{H}$, et al. Significance of renal rim grade on computed tomography in severity evaluation of acute pancreatitis. Pancreas. 2010 Jan. 39(1):41-6. [Medline].

26. Jee SL, Jarmin R, Lim KE, Raman K. Outcomes of early versus delayed cholecystectomy in patients with mild to moderate acute biliary pancreatitis: A randomized prospective study. Asian J Surg. 2016.07.010.

27. van Baal MC, Besselink MG, Bakker OJ, et al. Timing of chole- cystectomy after mild biliary pancreatitis: a systematic re- view. Ann Surg. 2012; 255(5):860e866.

28. Bakker OJ, van Santvoort HC, Hagenaars JC, et al. Timing of cholecystectomy after mild biliary pancreatitis. Br J Surg. 2011; 98(10):1446e1454.
29. Bakker OJ, Van Santvoort HC, Hagenaars JC, Besselink MG, Bollen TL, Gooszen HG, et al. Timing of cholecystectomy after mild biliary pancreatitis. Br. J. Surg. 2011; 98(10):1446-54.

30. Banks PA and Freeman ML. Practice guidelines in acute pancreatitis. Am.J Gastroenterol. 2006; 101(10):2379-2400.

31. Aboulian A, Chan T, Yaghoubian A, Kaji AH, Putnam B, Neville A, et al. Early cholecystectomy safely decreases hospital stay in patients with mild gallstone pancreatitis: a randomized prospective study. Ann Surg 2010; 251(4): 615-19.

32. Nealon WH, Bawduniak J and Walser EM. Appropriate timing of cholecystectomy in patients who present with moderate to severe gallstone-associated acute pancreatitis with peripancreatic fluid collections. Ann Surg 2004; 239(6):741-749.

33. Nebiker CA, Frey DM, Hamel CT, Oertli D and Kettelhack C. Early versus delayed cholecystectomy in patients with biliary acute pancreatitis. Surgery. 2009; 145(3):260-264.

34. Alimoglu O, Ozkan OV, Sahin M, Akcakaya A, Eryilmaz $R$ and Bas G. Timing of cholecystectomy for acute biliary pancreatitis: outcomes of cholecystectomy on first admission and after recurrent biliary pancreatitis. World J Surg. 2003; 27(3):256-59.

35. Mador BD, Panton ON, Hameed SM. Early versus delayed cholecystectomy following endoscopic sphincterotomy for mild biliary pancreatitis. Surg Endosc. 2014 Dec; 28(12):3337-42.

36. Pezzilli R, Uomo G, Gabbrielli A, Zerbi A, Frulloni L, De Rai $P$, et al. A prospective multicenter survey on the treatment of acute pancreatitis in Italy. Dig Liver Dis 2007; 39(9):838-846.

\begin{tabular}{|c|c|c|c|}
\hline \multicolumn{4}{|c|}{ AUTHORSHIP AND CONTRIBUTION DECLARATION } \\
\hline Sr. \# & Author-s Full Name & Contribution to the paper & Author $=\mathbf{s}$ Signature \\
\hline 1 & Mustma Kamal & $\begin{array}{l}\text { Main author, surgeon and } \\
\text { perform the procedure. }\end{array}$ & \\
\hline 2 & Naveed AKntal & colrect trie data. & \\
\hline 3 & Ghulam Murtaza & Analysis of data. & \\
\hline 4 & Najaf Azad & Review the literature. & \\
\hline
\end{tabular}

